\title{
Modelagem da Dinâmica de um Grupo de Indivíduos HIV Positivos com Parâmetro Fuzzy do Tipo 2
}

\author{
Eduard Rojas Castillo, $\quad$ Rosana Motta Jafelice, \\ Faculdade de Matemática, UFU, \\ 38408-100, Uberlândia, MG \\ E-mail: eduard_1510@hotmail.com,_rmotta@ufu.br,
}

\author{
Alessandro Alves Santana \\ Faculdade de Matemática \\ 38408-100, Uberlândia, MG \\ E-mail: alessandro@famat.ufu.br.
}

\begin{abstract}
Resumo: Neste trabalho estudamos a taxa de retorno de um grupo de indivíduos HIV positivos, de sintomáticos (presença de doenças oportunistas) para assintomáticos, utilizando tratamento antirretroviral. Construimos Sistemas Baseados em Regras Fuzzy (SBRF) para conjuntos fuzzy do tipo 1 e do tipo 2 com intuito de modelar a taxa de retorno desses indivíduos, dependendo da carga viral e do nível do linfócito $T$ do tipo $C D 4+$. O linfócito $T$ do tipo $C D 4+$ é o principal linfócito que o vírus ataca ao atingir a corrente sanguínea. Um dos SBRF do tipo 2 tem como saída um número real e o outro SBRF do tipo 2 utiliza o método de inferência de Mamdani e tem como saída um conjunto fuzzy unitário. A partir de dados laboratoriais do linfócito $T$ do tipo $C_{4}+$ e da carga viral de um grupo de indivíduos HIV positivos obtemos os valores das taxas de retorno através do SBRF do tipo 1 e dos dois SBRF do tipo a que são ajustados por superfícies através do método dos minimos quadrados. As três superfícies são comparadas e verificamos que as duas superfícies que melhor se ajustam aos valores das taxas de retorno de sintomáticos para assintomáticos são as obtidas pelos SBRF do tipo 2.
\end{abstract}

Palavras-chave: Conjuntos Fuzzy do Tipo 2, Mancha de Incerteza, HIV.

\section{Introdução}

A lógica fuzzy do tipo 1, também conhecida como lógica nebulosa ou lógica difusa, é capaz de trabalhar com a incerteza relacionada ao significado das palavras utilizando funções de pertinências precisas. Uma vez que as funções de pertinências do tipo 1 são definidas, toda incerteza relacionada com o significado das palavras desaparece, porque as funções de pertinência do tipo 1 são totalmente precisas [4] e [6]. A lógica fuzzy do tipo 2, por outro lado, modela a incerteza oriunda do significado das palavras. Embora a função de pertinência do tipo 2 também seja precisa, esta é composta por uma "mancha" de incerteza que permite que a incerteza seja trabalhada pelo SBRF do tipo 2 [4] e [6]. A lógica fuzzy do tipo 1 e do tipo 2 foram introduzidas por Lofti Zadeh em 1965 [8] e 1975 [10], respectivamente. Mendel et al. (2006) afirmam que SBRF do tipo 2 tem potencial para fornecer melhor desempenho do que um SBRF tipo 1. A lógica fuzzy pode ser uma ferramenta útil na abordagem de problemas em biomedicina, a aplicação dessa teoria na área médica tem demonstrado a sua capacidade para aprimorar e desenvolver tanto equipamentos quanto modelos nas mais diversas atividades de pesquisa e de diagnósticos.

Neste trabalho, utilizamos exames laboratoriais de carga viral e do linfócito T, do tipo CD4+ de dez indivíduos HIV positivos. Estes exames laboratoriais foram realizados em datas e em quantidade diferentes. Existe dificuldade de encontrar pessoas com disciplina para participar 
regularmente do programa de tratamento com antirretrovirais, devido a efeitos colaterais que os medicamentos provocam. Os resultados de exames laboratoriais de indivíduos que recebem tratamento com antirretrovirais apresentam uma variabilidade muito grande, o que dificulta sua padronização. Para modelar a carga viral e o linfócito T, do tipo CD4+, para estes indivíduos, construímos números fuzzy triangulares [7]. Em cada número fuzzy triangular consideramos o valor de pertinência 1 como sendo a média aritmética dos valores da carga viral, e do linfócito $\mathrm{T}$ do tipo $\mathrm{CD} 4+$ para cada instante de tempo, respectivamente. Para os valores da carga viral e do linfócito T do tipo CD4+ médios obtivemos a taxa de retorno através do SBRF do tipo 1 e através de dois SBRF do tipo 2, um com saída tendo um número real e o outro SBRF do tipo 2 que utiliza o método de inferência de Mamdani e tem como saída um conjunto fuzzy unitário. A partir destes valores determinamos três superfícies para a taxa de retorno, através dos método dos mínimos quadrados [5], que poderão fornecer previsões para indivíduos HIV positivos que tenham comportamento semelhante aos dos indivíduos estudados.

Na próxima seção apresentamos alguns conceitos importantes da teoria dos conjuntos fuzzy.

\section{Teoria dos Conjuntos Fuzzy}

Nesta seção apresentamos inicialmente definições dos conjuntos fuzzy do tipo 1 e em seguida, definimos alguns conceitos dos conjuntos fuzzy do tipo 2 .

\subsection{Conjunto Fuzzy do Tipo 1}

Definição 2.1. Um subconjunto fuzzy $F$ do conjunto universo $\mathcal{U}$ é definido em termos de uma função de pertinência u que a cada elemento $x$ de $\mathcal{U}$ associa um número $u(x)$, entre zero e um chamado de grau de pertinência de $x$ a $F$. Assim, o conjunto fuzzy $F$ é simbolicamente indicado por sua função de pertinência

$$
u_{F}: \mathcal{U} \longrightarrow[0,1]
$$

Os valores $u_{F}(x)=1$ e $u_{F}(x)=0$ indicam, respectivamente, a pertinência plena e a não pertinência do elemento $x$ a $F$.

Definição 2.2. Uma norma triangular (t-norma) é uma operação binária $t:[0,1] \times[0,1] \rightarrow$ $[0,1]$ satisfazendo as seguintes condições: Comutatividade: $x t y=y t x ;$ Associatividade: $x t(y t z)=$ (xty)tz; Monotonicidade: Se $x \leq y$ e $w \leq z$ então $x t w \leq y t z$ e Condições de fronteira: $0 t x=0$, $1 t x=x$.

Definição 2.3. Sejam $X$ e $Y$ dois conjuntos não vazios. Um grânulo fuzzy é um subconjunto fuzzy de $X \times Y$ com grau de pertinência dado por:

$$
u_{A \times B}(x, y)=u_{A}(x) t u_{B}(y), \forall(x, y) \in A \times B
$$

onde, $A \subset X, B \subset Y$ e t-norma. Neste trabalho, utilizamos o operador minimo que é uma t-norma.

Definição 2.4. SBRF para conjuntos fuzzy do tipo 1 (SBRF1) contêm quatro componentes: um processador de entrada que realiza a fuzzificação dos dados de entrada, uma coleção de regras nebulosas chamada base de regras, uma máquina de inferência fuzzy e um processador de saída que fornece um número real como saída. O método de inferência utilizado neste trabalho é o Método de Inferência de Mamdani. 


\subsection{Conjunto Fuzzy do Tipo 2}

Definição 2.5. Um conjunto fuzzy $\tilde{A}$ do tipo 2 , é caracterizado por uma função de pertinência $\mu_{\tilde{A}}(x, u)$ do tipo 2 , onde $x \in X$ e $u \in J_{x} \subseteq[0,1]$, ou seja:

$$
\tilde{A}=\left\{\left((x, u), \mu_{\tilde{A}}(x, u)\right): \forall x \in X, \forall u \in J_{x} \subseteq[0,1]\right\}
$$

onde, $0 \leq \mu_{\tilde{A}}(x, u) \leq 1$.

Definição 2.6. Um conjunto fuzzy do tipo 2 é intervalar quando todos os valores de $\mu_{\tilde{A}}(x, u)$ são unitários, ou seja, $\mu_{\tilde{A}}(x, u)=1$, veja Figura 1 .

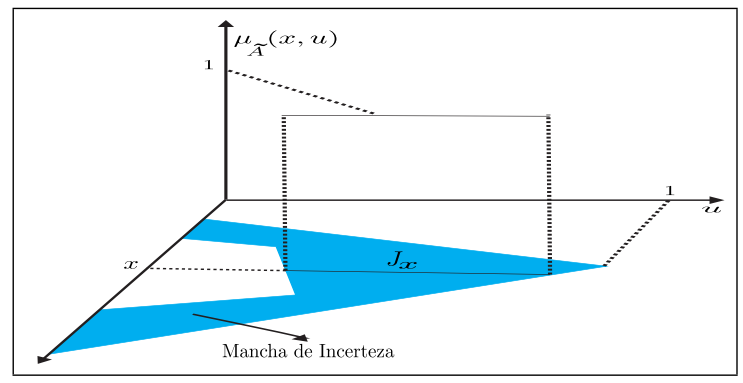

Figura 1: Conjunto fuzzy do tipo 2 intervalar.

Definição 2.7. SBRF do tipo 2 (SBRF2) é composto por cinco componentes: fuzzificador, inferência, base de regras, reduzidor do tipo 1 e defuzzificador. Este sistema é composto por, no mínimo, um conjunto fuzzy do tipo 2 presente em um dos antecedentes ou no consequente que compõem uma das regras que formam o sistema. A descrição do SBRF2 é apresentada na Figura 2.

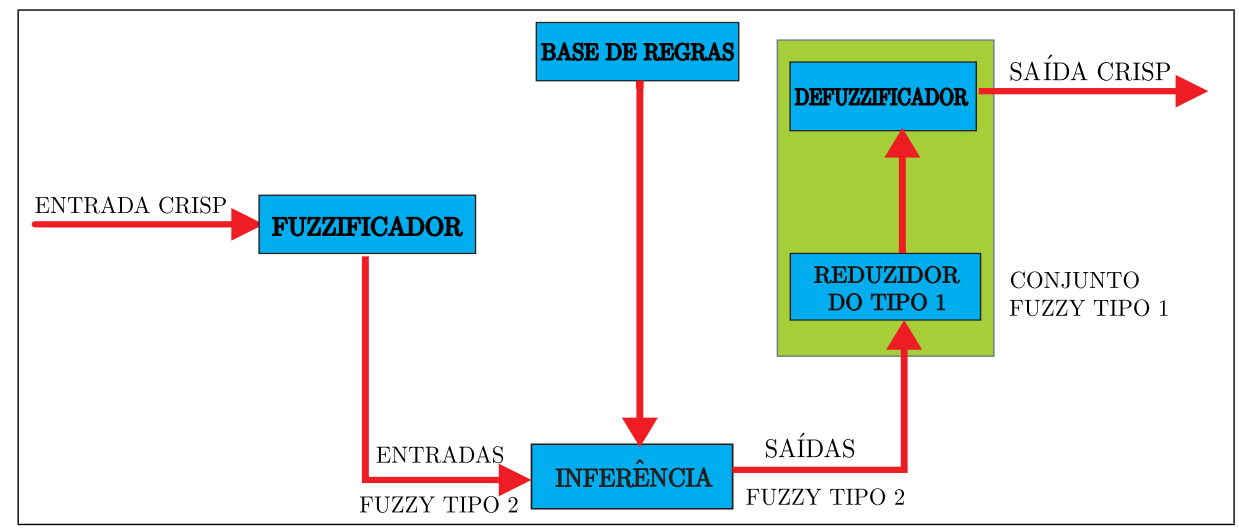

Figura 2: Sistema Baseado em Regras Fuzzy do tipo 2 [6].

\subsubsection{Saída de SBRF2 é um Intervalo}

Considere a base de regras de um SBRF2 intervalar dada a seguir:

$$
R^{n}: \text { SE } x_{1} \text { é } \widetilde{X}_{1}^{n} \text { e } x_{2} \text { é } \widetilde{X}_{2}^{n} \text { e } \cdots \text { e } x_{I} \text { é } \widetilde{X}_{I}^{n} \text {, ENTÃO } y \text { é } Y^{n}, n=1,2, \cdots, N
$$

onde; $\widetilde{X}_{i}^{n}$ são conjuntos fuzzy do tipo $2, i=1,2, \cdots, I$ e $Y^{n}=\left[\underline{y}^{n}, \bar{y}^{n}\right]$ é um intervalo o que pode ser entendido como o centroide, de um consequente. Quando $\underline{y}^{n}=\bar{y}^{n}$, ou seja, cada regra consequente é um número real. Suponha que o vetor de entrada é $x^{\prime}=\left(x_{1}^{\prime}, x_{2}^{\prime}, \cdots, x_{I}^{\prime}\right)$, calculamos $y_{l}$ e $y_{r}$ utilizando o algoritmo de Karnik-Mendel [4] e determinamos o intervalo $\left[y_{l}, y_{r}\right]$. Os detalhes dos cálculos podem ser encontrados em [9]. A saída defuzzificada é dada por:

$$
y=\frac{y_{l}+y_{r}}{2} \text {. }
$$




\subsubsection{Saída de SBRF2 é um Conjunto Fuzzy do Tipo 2 Intervalar}

Neste caso, a base de regras de um SBRF2 intervalar apresentada da seguinte forma:

$$
R^{n}: \text { SE } x_{1} \text { é } \widetilde{X}_{1}^{n} \text { e } x_{2} \text { é } \widetilde{X}_{2}^{n} \text { e } \cdots \text { e } x_{I} \text { é } \widetilde{X}_{I}^{n} \text {, ENTÃO } y \text { é } Y^{n}, n=1,2, \cdots, N
$$

onde; $\widetilde{X}_{i}^{n}, Y^{n}$ são conjuntos fuzzy do tipo $2, i=1,2, \cdots, I$. Suponha que o vetor de entrada é $x^{\prime}=\left(x_{1}^{\prime}, x_{2}^{\prime}, \cdots, x_{I}^{\prime}\right)$, o método de inferência utilizado é o de Mamdani para conjuntos do tipo 2 [2] e [6]. Calculamos $y_{l}$ e $y_{r}$ utilizando o algoritmo de Karnik-Mendel [4] e determinamos o intervalo $\left[y_{l}, y_{r}\right]$. A saída defuzzificada é dada por:

$$
y=\frac{y_{l}+y_{r}}{2} .
$$

\section{Modelo Fuzzy}

Para avaliar a eficiência do tratamento, os especialistas da área médica têm grande interesse em quantificar a taxa de retorno à classe dos indivíduos sintomáticos para os indivíduos assintomáticos. Assim, em [3] sugere as seguintes equações diferenciais para representar matematicamente a evolução da população sintomática para a população assintomática com adesão regular ao tratamento:

$$
\begin{cases}\frac{d x}{d t}=\gamma(v, c) y=\gamma(v, c)(1-x) & x(0)=0 \\ \frac{d y}{d t}=-\gamma(v, c) y & y(0)=1\end{cases}
$$

onde, $x=x(t)$ é a proporção da população assintomática, no instante $t, y=y(t)$ é a proporção da população sintomática, no instante $t$ e $\gamma$ é a taxa de retorno da população sintomática para assintomática, que depende das variáveis carga viral $(v)$ e nível de CD4+ $(c)$ obtida através de um SBRF. Assumimos que $x+y=1$, e, portanto, uma vez resolvida a equação para $y$, podemos encontrar $x=1-y$. As variáveis de entrada dos SBRF são trapezoidais apresentadas na Figura 3, as linhas internas em preto representam as funções de pertinências do SBRF1 e as manchas de incerteza coloridas representam as funções de pertinência dos SBRF2. Vamos estimar a taxa de retorno $\gamma(v, c)$ baseada nas informações médicas.
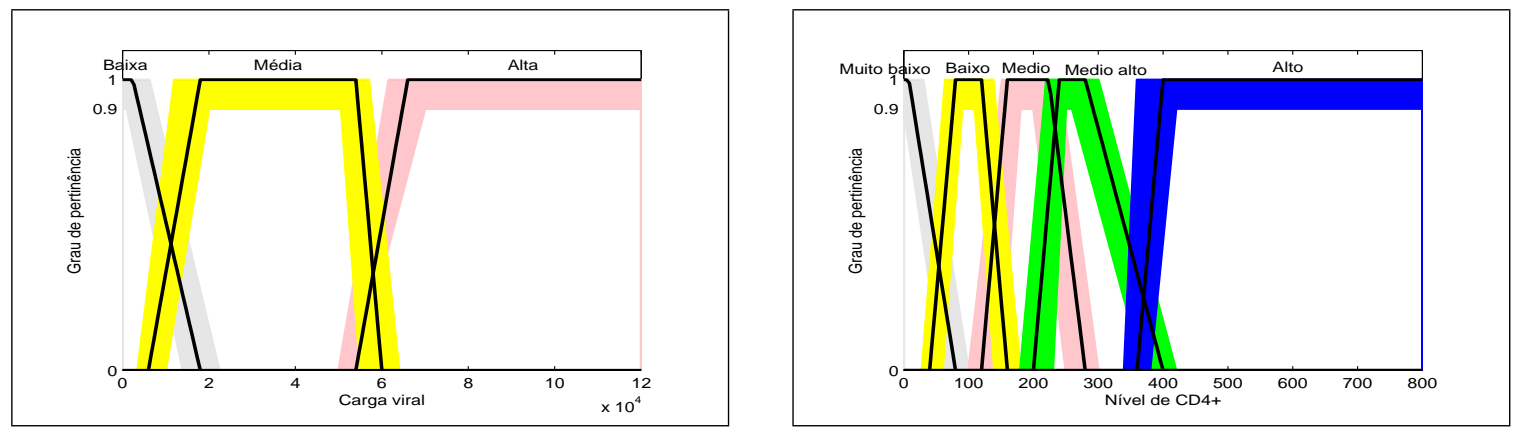

Figura 3: Funções de pertinência da carga viral e do nível de CD4+.

\section{Modelo Fuzzy para um Grupo de Indivíduos HIV Positivos}

Realizamos o estudo, a partir de dados de exames laboratoriais do linfócito $\mathrm{T}$, do tipo CD4+ e da carga viral de dez pacientes do Ambulatório Herbert de Souza em UberlândiaMG. Consideramos o primeiro exame do linfócito T, do tipo CD4+ e da carga viral, de cada indivíduo, como sendo o tempo inicial $t=0$ (meses) e em seguida, somamos o número de meses 
para o próximo exame, e assim sucessivamente. Assim, construímos os dados para os exames laboratoriais do nível de CD4+ e para os exames da carga viral para cada indivíduo variando no tempo. Como os dados laboratoriais apresentam muita variabilidade, optamos por calcular a média aritmética em cada instante $t$ para a carga viral e o linfócito $\mathrm{T}$, do tipo CD4+. Por exemplo: em $t=0$ meses, na Tabela 4; temos os dados de dez indivíduos HIV positivos (Ind) dos exames de carga viral $(v)$ e do nível de CD4+ $(c)$; e a média aritmética (MA) de $v$ e $c$ para estes indivíduos.

Este procedimento é realizado 47 vezes para exames laboratoriais da carga viral $(v)$ e do nível de CD4+ (c) destes indivíduos, em um intervalo de tempo entre 0 e 72 meses. Esses exames laboratoriais nem sempre são realizados com o mesmo intervalo de tempo.

\begin{tabular}{cccccccccccc}
\hline & Ind $_{1}$ & Ind $_{2}$ & Ind $_{3}$ & Ind $_{4}$ & Ind $_{5}$ & Ind $_{6}$ & Ind $_{7}$ & Ind $_{8}$ & Ind $_{9}$ & Ind $_{10}$ & MA \\
\hline$v$ & 50 & 1304 & 120000 & 466 & 110000 & 86000 & 44000 & 7900 & 100000 & 10000 & 47972 \\
$c$ & 324 & 333 & 533 & 236 & 216 & 236 & 260 & 443 & 467 & 230 & 327.8 \\
\hline
\end{tabular}

Tabela 1: Resultados dos exames de carga viral (cópias de RNA/ml) e nível de CD4+ (células $/ \mathrm{mm}^{3}$ ).

\subsection{Construção dos Grânulos}

Construímos os números fuzzy triangulares, assumindo grau de pertinência zero no valor mínimo e máximo da carga viral e do nível de $\mathrm{CD} 4+$; e grau de pertinência um na média aritmética dos dados $v$ e $c$, em cada instante de tempo, como apresentados na Figura 4.
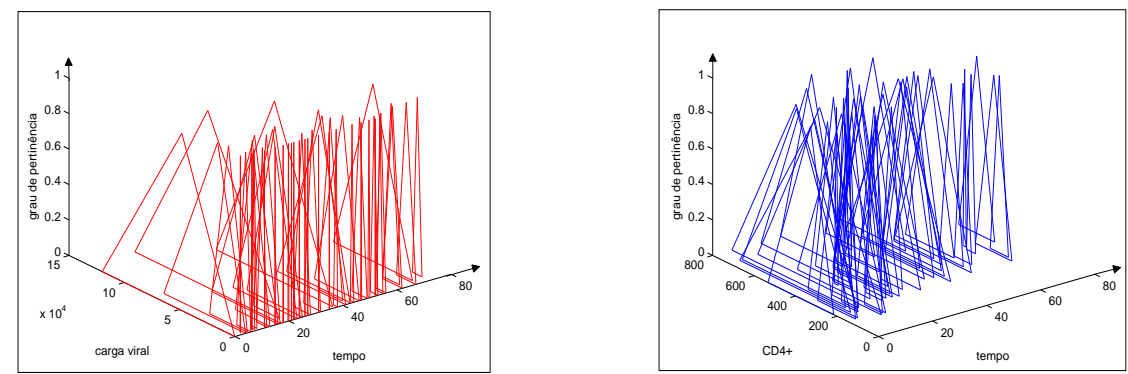

Figura 4: Números fuzzy triangulares.

Para construir, o grânulo tomamos o número fuzzy triangular no eixo $x$ (Carga viral) e no eixo y (Nível de CD4+) para cada $t$ fixo. A seguir, apresentamos informações sobre as saídas e as bases de regras dos SBRF.

\section{- SBRF do Tipo 1}

A taxa de retorno é dada por conjuntos fuzzy unitário [1]. A Tabela 2 foi construída levando em consideração as informações do especialista da área.

\section{- Saída do SBRF do Tipo 2 é um Número Real}

Os valores das taxas de retorno são dadas pelos números reais onde os conjuntos fuzzy unitários tem grau de pertinência maior que zero, isto é, nos suportes dos conjuntos fuzzy unitários. A Tabela 3 apresenta as regras fuzzy para este SBRF2.

\section{- Saída do SBRF do Tipo 2 é um Conjunto Fuzzy Unitário}

A taxa de retorno é dada por conjuntos fuzzy unitário. A base de regras fuzzy é a mesma da Tabela 2.

\subsection{Comparações entre as Superfícies}

Determinamos a taxa de retorno de sintomático para assintomático para a média dos exames laboratoriais da carga viral e do nível de CD4+ do grupo de indivíduos estudado através 
Proceeding Series of the Brazilian Society of Applied and Computational Mathematics, Vol. 3, N. 1, 2015.

\begin{tabular}{lccc}
\hline \multirow{2}{*}{$\mathrm{CD} 4+(c)$} & \multicolumn{3}{c}{ Carga Viral $(v)$} \\
\cline { 2 - 4 } & Baixa & Média & Alta \\
\hline Muito Baixo & Fraca & Fraca & Fraca \\
Baixo & Média fraca & Fraca & Fraca \\
Médio & Média fraca & Média fraca & Média fraca \\
Médio Alto & Média & Média & Média fraca \\
Alto & Forte & Fraca & Fraca \\
\hline
\end{tabular}

Tabela 2: Base de regras do SBRF1.

\begin{tabular}{lccc}
\hline \multirow{2}{*}{ CD4+ $(c)$} & \multicolumn{3}{c}{ Carga Viral $(v)$} \\
\cline { 2 - 4 } & Baixa & Média & Alta \\
\hline Muito Baixo & 0 & 0 & 0 \\
Baixo & 0.15 & 0 & 0 \\
Médio & 0.15 & 0.15 & 0.15 \\
Médio Alto & 0.65 & 0.65 & 0.15 \\
Alto & 1 & 0 & 0 \\
\hline
\end{tabular}

Tabela 3: Base de regras do SBRF2.

dos métodos apresentados na seção 2. Os programas utilizados para obter estes valores foram fornecidos por [2] e [9]. Depois de vários testes realizados no toolbox "sftool" do Matlab, encontramos a função (5) de duas variáveis através do método dos mínimos quadrados e observando que o valor do coeficiente de determinação $\left(r^{2}\right)$ deve estar próximo de 1 . A Figura 5 apresenta um comportamento compatível com o que ocorre, em geral, segundo o especialista na área da saúde, quando a carga viral está alta e o nível de CD4+ está baixo então a taxa de retorno de sintomático para assintomático está próxima de zero. E quando a carga viral está baixa e o nível de CD4+ está alto então a taxa de retorno está próxima de 1.

$$
\gamma_{i}(v, c)=a_{i} \exp \left(-v^{4}\right)-b_{i} c^{2}+c_{i} v+d_{i} c-e_{i} v c-f_{i} c^{0.1}, i=1,2,3
$$

onde: $\gamma_{1}, \gamma_{2}$ e $\gamma_{3}$, estão relacionados com os valores da taxa de retorno obtidos pelo SBRF1, SBRF2 com saída dada por um número real e SBRF2 com saída dada por um conjunto fuzzy unitário, respectivamente. Os valores dos parâmetros são: $a_{1}=0.2568, a_{2}=0.8258, a_{3}=0.3998$, $b_{1}=0.00000533, b_{2}=0.000005295, b_{3}=0.000005202, c_{1}=0.000001684, c_{2}=0.000002338, c_{3}=$ $0.000002183, d_{1}=0.006225, d_{2}=0.006173, d_{3}=0.006071, e_{1}=0.00000001572, e_{2}=0.000000016$, $e_{3}=0.00000001639, f_{1}=0.4293, f_{2}=0.4187, f_{3}=0.404$ e os coeficientes de determinação, de cada uma destas superfícies são dadas por: $r_{1}^{2}=0.793, r_{2}^{2}=0.8375, r_{3}^{2}=0.8308$. A Figura 5 foi obtida pelo SBRF2 com saída dada por um número real que tem o coeficiente de determinação mais próximo de 1.

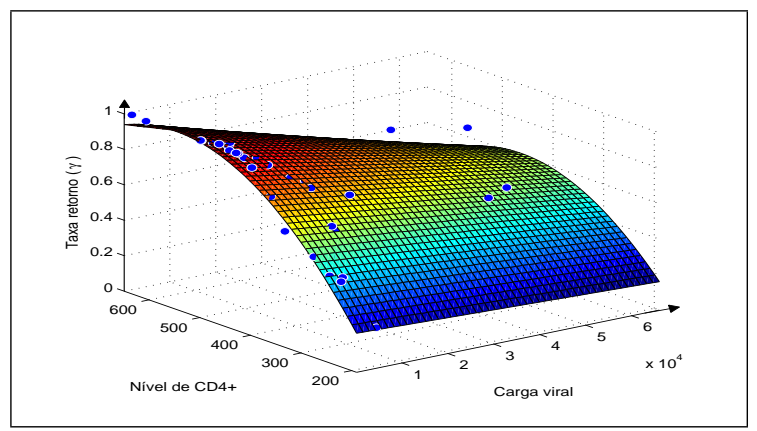

Figura 5: Superfície de ajuste dos dados de carga viral e nível de CD4+ médios obtidos usando SBRF2 com saída dada por um número real.

Para representar o exame laboratorial de um indivíduo HIV positivo que tem um comportamento similar do grupo estudado, calculamos um valor aleatório para carga viral e para o nível de CD4+ no tempo $t=0$. Neste caso, a carga viral varia entre 50 a 120000 (cópias de $\mathrm{RNA} / \mathrm{ml}$ ) e o nível de CD4+ de 216 a 533 (células $/ \mathrm{mm}^{3}$ ), o valor aleatório obtido para a carga viral é 18956 (cópias de RNA/ml) e para o nível de CD4+ é 369 (células $/ \mathrm{mm}^{3}$ ). Através dos números fuzzy triangulares para a carga viral e para o nível de CD4+ obtivemos os graus de pertinência aproximados para os dois valores aleatórios, que são 0.39 e 0.63 , respectivamente. Como sabemos, o grânulo fuzzy permite computar o grau de pertinência do produto cartesiano entre a carga viral e o nível de CD4+, assim, calculando o mínimo entre estes valores, temos que o indivíduo tem grau de pertinência 0.39 para pertencer à média do grupo estudado. Assim, este indivíduo pode observar que está com grau de pertinência baixo para pertencer à média do 
grupo em $t=0$. Também, podemos obter a taxa de retorno de sintomático para assintomático através da equação $(5)$, que é dada por $\gamma_{1}(18956,369)=0.718, \gamma_{2}(18956,369)=0.7287$ e $\gamma_{3}(18956,369)=0.729$, para este instante. Porém, as taxas de retorno obtidas para este indivíduo são otimistas porque os ajustes (5) foram obtidos para os valores de carga viral e do nível de CD4+ médios; e o grau de pertinência do indivíduo em estudo é 0.39 em relação aos valores da carga viral e do nível de CD4+ médios do grupo de indivíduos. Este estudo pode colaborar no sentido de ajudar o indivíduo na tomada de uma decisão, isto é, indicar se a terapia antirretroviral utilizada está adequada e inferir se o indivíduo está tendo qualidade de vida.

\section{Conclusão}

A aplicação da teoria dos conjuntos fuzzy em dados com alta variabilidade como os exames laboratoriais de carga viral e nível de CD4+ foi fundamental, pois possibilitou a construção de números fuzzy triangulares e a obtenção da taxa de retorno para o grupo estudado. Esta taxa pode ser obtida para outros grupos de indivíduos que tenham adesão regular ao tratamento com antirretrovirais. As superfícies obtidas pelos método dos mínimos quadrados com os valores das taxas de retorno dos indivíduos HIV positivos de sintomático para assintomático dos SBRF2 apresentaram uma melhor aproximação do que a obtida com os valores gerados pelo SBRF1, pois os coeficientes de determinação ficaram mais próximos de 1 .

\section{Agradecimentos}

O primeiro autor agradece à CAPES pela Bolsa de Mestrado e a segunda autora agradece à FAPEMIG e à CAPES pelo auxílio financeiro concedido para a apresentação deste trabalho.

\section{Referências}

[1] E.R. Castillo, R.S.M. Jafelice e A.A. Santana, Modelagem Fuzzy da Taxa de Retorno de um Grupo de Indivíduos HIV Positivos Sintomáticos para Assintomáticos, Anais da SEMAP, 2013.

[2] J.R. Castro, O. Castillo e L.G. Martínez, "Interval Type-2 Fuzzy Logic Toolbox", Engineering Letters, 2007.

[3] R.S.M. Jafelice, "Modelagem Fuzzy para Dinâmica de Transferência de Soropositivos para HIV em Doença Plenamente Manifesta", Tese de Doutorado, FEEC-Unicamp, 2003.

[4] J. Mendel, R. John, R. e F.T. Liu, Interval Type-2 Fuzzy Logic Systems Made Simple, IEEE Transactions on Fuzzy Systems, 14 (6) (2006) 808-821.

[5] M.A.G. Ruggiero e V.L.R. Lopes, "Cálculo Numérico Aspectos Teóricos e Computacionais", UNICAMP, $2^{\text {a }}$ edição, 2006.

[6] P.M.S. Rizol, L. Mesquita e O. Saotome, Lógica Fuzzy Tipo-2, Revista Sodebras, 6 (2011) $27-46$.

[7] J.M.F. Santos, "Interpolação Difusa de Fenómenos Geográficos", Tese de Doutorado, Universidade de Coimbra, 2004.

[8] L.A. Zadeh, Fuzzy Sets, Information and Control, 8 (1965) 338-353.

[9] D. Wu e M. Nie, Comparison and practical implementation of type-reduction algorithms for type-2 fuzzy sets and systems, Proc. IEEE Intl Conf. on Fuzzy Systems, Taipei, Taiwan, 2011.

[10] L.A. Zadeh, The Concept of a Linguistic Variable and its Application to Approximate Reasoning-1, Information Science, 8 (1975) 199-249. 